\title{
UMA ANTROPOLOGIA DAS COISAS: ETNOGRAFIA E MÉTODO
}

\author{
MESSIAS BASQUES ${ }^{1}$ \\ UFSCAr
}

RESUMO: O presente ensaio bibliográfico tem como base o livro que resultou de uma série de discussões promovidas por um grupo de estudantes de doutorado do Departamento de Antropologia Social da Universidade de Cambridge, no final da década de 1990. Não obstante a diversidade dos contextos etnográficos, todos os autores partilham o desafio de reformular a relação entre o método etnográfico e a teoria antropológica no que concerne ao estudo daquilo que se convencionou chamar de "cultura material". Donde o título "Pensando Mediante as Coisa"s, além de denotar uma questão antropológica a respeito do que os informantes fazem e de como os autores poderiam desenvolver versões sobre os modos a partir dos quais os mesmos apreendem e concebem as coisas, também compreenda o caráter principal dos encontros que motivaram a redação deste livro.

PALAVRAS-CHAVE: etnografia; metodologia; ontologias nativas; teoria antropológica.

ABSTRACT: This bibliographic essay is based on the book that resulted from a series of discussions promoted by a group of doctoral students in the Department of Social Anthropology at Cambridge University in late 1990s. Despite the diversity of ethnographic contexts, all authors share the challenge of recasting the relationship between anthropological theory and ethnographic method in relation to the study of what is conventionally called material culture. Hence the title "Thinking Through Things", besides denoting an anthropological question about what informants do, and how the authors could develop versions on the ways from which they perceive and conceive of things also includes the main character of the meetings that led to the writing of this book.

KEYWORDS: ethnography; methodology; native ontology; anthropological theory.

Este ensaio bibliográfico tem como base o livro Thinking Through Things (HENARE et al, 2007, 248 p.), que resultou de uma série de discussões promovidas por um grupo de estudantes de doutorado do Departamento de Antropologia Social da Universidade de Cambridge, no

\footnotetext{
${ }^{1}$ Mestrando do Programa de Pós-Graduação em Antropologia Social da Universidade Federal de São Carlos (PPGAS-UFSCar), Bolsista FAPESP. E-mail: messias.basques@gmail.com .
}

Espaço Ameríndio, Porto Alegre, v. 4, n. 1, p. 150-165, jan./jun. 2010. 
MESSIAS BASQUES - Uma antropologia das coisas...

final da década de 1990. Não obstante a diversidade dos contextos etnográficos, todos os autores partilham o desafio de reformular a relação entre o método etnográfico e a teoria antropológica no que concerne ao estudo daquilo que se convencionou chamar cultura material. Em tom de manifesto, a Introdução oferece uma síntese dos oito capítulos que compõem o livro, cujo objetivo comum consiste em propor alternativas às seguintes questões: Seria possível conceber uma antropologia orientada por artefatos que não se resuma, ainda assim, a estudos de cultura material? E poderia tal projeto ser desenvolvido não apenas como um novo subgênero da disciplina, mas antes como meio para reconfigurar a análise antropológica em geral?

Em vez de apontar en passant alguns aspectos do livro, penso que a exposição de seus fundamentos teóricos bem como de cada um dos capítulos pode lançar luz sobre questões cujo alcance excede o interesse mais imediato que sua leitura despertará em estudiosos de cultura material, expressões artísticas, coleções arqueológicas e museus de etnologia. Thinking Through Things é uma obra digna de nota pela fecundidade das críticas etnográficas a conceitos tais como os de agência, socialidade, ontologia, entre outros que passaram a ocupar um espaço cada vez maior nas pesquisas antropológicas das últimas décadas. Antes de dar início a este ensaio bibliográfico, remeto o leitor a uma anedota.

O alienista, do livro homônimo de Machado de Assis, certa vez foi indagado por um boticário insatisfeito com a pretensa "revolução" que o personagem queria protagonizar no mundo das idéias médicas. $\mathrm{O}$ boticário defendia que "nem todas as instituições do antigo regime mereciam o desprezo do nosso século". Em contraponto, o alienista respondeu: "Há melhor do que anunciar a minha idéia; é praticá-la" (MACHADO DE ASSIS, 1992, p. 18). Desatinados perante a ortodoxia da disciplina - ou tidos como iconoclastas de conceitos tais indivíduo e sociedade, natureza e cultura -, muitos antropólogos tem sido vistos como candidatos à Casa de Orates. Sobretudo aqueles que desde os anos 1980 passaram a figurar uma guinada em face das teorias que os encontros etnográficos suscitam e promovem. Trata-se de um afastamento dos apriorismos implicados na tarefa de 'interpretação' e de uma defesa da experimentação e de descrições formuladas mediante 
MESSIAS BASQUES - Uma antropologia das coisas...

as coisas, em trabalhos de campo quaisquer. Noutras palavras, ao invés de falar por ou no lugar de, trata- se de dispor a reflexão (me)diante as coisas, pois estas devem importar mais que todos os nossos pontos de vista sobre as mesmas. Boticários e alienistas à parte, não se trata de instaurar uma polêmica tal aquela cultivada em torno de autores como Gabriel Tarde (2007), mas antes de propor outras margens às teorias etnográficas. Outras margens que não somente as duas da lógica das “alternativas infernais" (PIGNARRE e STENGERS, 2005).

E o livro ora debatido pode ser visto como uma coletânea de experimentos etnográficos motivados por desafios similares, cujos eixos consistem justamente numa problematização dos "grandes divisores" responsáveis pelo estabelecimento da antropologia como disciplina. Todavia, para além (e aquém) da crítica anacrônica que remonta à desnecessária eleição de outros 'pais fundadores', os autores deste livro procuraram extrair as conseqüências empíricas e teóricas desse posicionamento em face de suas respectivas pesquisas de campo. O objetivo é reunir uma gama de iniciativas que procuram demonstrar como certos momentos de 'revelações' etnográficas - nas quais coisas imprevistas e não concebidas previamente se tornam aparentes - devem ser levados a sério no discurso antropológico. E, em particular, tendo- se em mente duas questões que aqui são centrais: Como e em que medida poderíamos falar dos artefatos implicados nestas ocasiões? E o que aconteceria se este 'estranhamento' propiciasse um estado de suspensão no qual resistíssemos à necessidade de explicá- los? (HENARE et al, 2007).

Tim Ingold disse certa vez que "a cultura é concebida como algo que paira sobre o mundo material, mas que não o permeia" (2000, p 340 - grifos meus). Neste modelo analítico, certamente majoritário, significados imbricam-se a coisas, impondo-se sobre elas, e são até mesmo inscritos ou incorporados a certas coisas. Mas são sempre presumidos, numa primeira instância, como distintos em face das mesmas. Um dos efeitos daí resultantes refere-se ao fato do próprio 'sistema' tornar-se o objeto de estudo, sendo seus artefatos reduzidos a ilustrações. A título de exemplificação, lembremos o exercício desenvolvido por Claude Lévi-Strauss em "Olhares sobre os objetos" (1995). Ao inventariar uma vasta série de diferentes estatutos que os 
MESSIAS BASQUES - Uma antropologia das coisas...

objetos possuem em contextos etnográficos que vão dos povos ameríndios à preocupação cotidiana de uma senhora japonesa com seu vestuário - "de quem me contaram (mas o caso não é provavelmente excepcional) que lavava a roupa todos os dias com medo de deixar roupa suja atrás de si, caso morresse subitamente" (LÉVI-STRAUSS, 1995, p. 153) -, Claude Lévi-Strauss procede por um método que assume uma distinção basilar entre categorias de pensamento e a cultura material que Ihe seria correspondente. Em contraste, o exercício desenvolvido pelos autores desta coletânea trata significado e coisa como uma identidade; significados não são 'transmitidos' por coisas, mas são idênticos a elas. Assim é deslocada a discussão a respeito das 'teorias' que poderiam ser mais ou menos apropriadas ao material etnográfico, no sentido de articular um método através do qual o 'material' possa enunciar seus próprios significados (HENARE et al, 2007).

Curioso notar que este movimento tem se convertido numa voga (ainda que para os alienistas de plantão seja, antes de tudo, matéria de moda), pois ressoa até mesmo no interessante livro de um autor situado noutras margens, a saber, a "antropologia do contemporâneo" de Paul Rabinow (2008) e sua abertura a pensar a etnografia como olhar adjacente enquanto método. Adjacente no sentido de que se mantém em estreita proximidade com o seu 'objeto', mas num intervalo ou ponto de simetria convertido em espaço de problematização. E isto por que não se trata de decalcar da filosofia uma reflexão em termos de transcendência ou imanência, mas tão somente de formular uma alternativa metodológica que seja capaz de apreender potencialidades, multiplicidades, e de criar um espaço de suspensão no qual a reflexão não se coadune ao crivo da dedução, mas antes ao raciocínio indutivo. Dos processos, atores e práticas à teoria.

Vis-à- vis, a iniciativa coletiva que culminou no livro Thinking Through Things foi motivada pelo desafio de conceber outra maneira de abordar as atividades do campo e da análise. O objetivo da metodologia proposta é o de tomar as 'coisas' encontradas no campo do modo mesmo como elas se apresentam, ao invés de assumir imediatamente que eles significam, representam, ou de que estariam em função de algo mais. Assim, os autores adotam uma abordagem que denominam 
MESSIAS BASQUES - Uma antropologia das coisas...

"radicalmente essencialista", uma vez que os trabalhos reunidos no livro podem ser vistos como tentativas mais abertas à proposição de abordagens heuristicamente preocupadas com a análise e que problematizam as 'coisas', como e quando elas surgem, em face da possibilidade de oferecer alternativas teóricas. Muito resumidamente, estas seriam as principais formulações da Introdução aos textos desta coletânea.

Já no segundo capítulo, Adam Reed (2007) nos fala da ação dos cigarros numa prisão de Papua Nova Guiné, na qual o "Smuk é Rei". A seu ver, o cigarro equivale à quintessência da vida na prisão, pois ainda que seu consumo seja proibido, sua circulação mantém ativa a economia informal dos internos. A prática do fumo também faz operar toda uma linguagem de gestos e atos, configurando uma ética e uma estética das relações entre os mesmos. E o autor nos fala da socialidade prisional que se dá mediante estes objetos, considerando o significado dos cigarros como artefato do encarceramento, além de explorar a possibilidade de tomar o próprio encarceramento como um artefato do fumo e da ação dos cigarros. Segundo os internos, o fumo é "Rei" justamente por que é $\mathrm{o}$ ator dominante da prisão. $\mathrm{O}$ consumo compulsivo de cigarros evoca a figura por eles denominada "homenscigarro", personagens que aparecem como que consumidos pelos próprios cigarros de que dispõem e/ ou pela sensação de abstinência que vez por outra os acomete. Tal objeto-fetiche, entretanto, não é animado por algo que the seja exterior - como uma intencionalidade humana -, mas por algo que é imamente à prática do seu consumo.

Dos cigarros da prisão de Bomana passamos à etnografia dos objetos conhecidos como taonga pelo povo Maori. Habitantes da Nova Zelândia, os Maori possuem conceitos que põem em xeque as noções ocidentais de propriedade material, fazendo surgir controvérsias em torno da regulamentação jurídica de bens os mais diversos. Amiria Henare (2007) nos dá mostras de como o conceito de taonga abrange coisas que vão dos ossos de baleia às plantas nativas, além dos conhecimentos e da própria língua Maori. A autora passa em revista os argumentos de Marcel Mauss no seu "Ensaio sobre o Dom", quando expôs a tese de que taonga seria um 'veículo' para o hau e o mana?.

\footnotetext{
${ }^{2}$ Cf. Marcel Mauss (2003).
}

Espaço Ameríndio, Porto Alegre, v. 4, n. 1, p. 150-165, jan./jun. 2010. 
MESSIAS BASQUES - Uma antropologia das coisas...

Para Henare, o que os Maori efetivamente dizem é que quando um taonga é trocado por outro não é simplesmente o hau do Dom que é transmitido, pois trata-se do hau ele mesmo. Ou seja, haveria uma "identidade" ou relação de pressuposição recíproca entre coisa e espírito, aspecto que Mauss separou em sua análise. Numa discussão similar a de François Jullien (2001), no seu livro "Fundar a Moral", Henare problematizará assim a questão da intradutibilidade do conceito de taonga nos termos de nossas línguas Euro-Americanas, tão marcadamente acostumadas a distinções que não se aplicam aos conceitos Maori.

No capítulo de número quatro desta coletânea, Sari Wastell (2007) trata da "res judicata" e da realeza divina na Suazilândia. A relação das "coisas legais" - provenientes dos sistemas jurídicos ocidentais vigentes desde o período colonial - em face do código procedente da figura divina do Rei suazi cria uma situação de contraste quando se trata da objetivação de "sistemas legais" tão díspares, ainda que presentes de modo concomitante no imaginário popular. E o leitor perceberá alguma semelhança entre o trabalho de Wastell e o de Marshall Sahlins (1985), sobre o Capitão Cook, embora não se trate aqui de uma análise histórico-estrutural, pois no caso da Suazilândia o englobamento do "outro" o preserva enquanto tal, numa relação de dissimilaridade contínua. Em suma, o que Wastell se propõe a perquirir são os contextos em que a lei não é uma coisa no mundo, mas antes a materialização do próprio mundo. E isto por que um dos modos de se referir ao Rei é empregando a expressão a língua que não conta mentiras: o que sua Majestade diz, simplesmente é. Eis aqui uma entidade que constitui o mundo no ato mesmo da emissão de seus pronunciamentos. $\mathrm{E}$ os suazis, por sua vez, movem-se entre (e mediante) conceituações incomensuráveis de poder, como índices da alteridade ontológica da realeza.

De volta à Papua Nova Guiné, temos o capítulo de Andrew Moutu (2007), que nos fala da possibilidade de ver a prática da criação de coleções como modos de ser, propondo uma alternativa às formulações que conferem primazia ao ato de classificação. Do entendimento do pensar como ato classificatório por excelência, passamos à prática de colecionar como instância do ser. Para tanto, sua etnografia 
MESSIAS BASQUES - Uma antropologia das coisas...

acompanhou os esforços que o povo latmul empregou na composição de coleções a partir dos destroços e ruínas de um tsunami que os acometeu. Ademais, como já havia demonstrado em 1958 Gregory Bateson (2008), o povo latmul recorre regularmente à justaposição de analogias para explicar coisas e eventos, questão que também denota a inadequação da concepção ocidental de colecionismo como prática de fetiche individual. Segundo Moutu (2007), pensar as coleções em termos dos procedimentos de classificação implica a projeção de uma perspectiva epistemológica à vida social latmul, suas relações e situações de contingência. Em defesa de seu argumento, o autor ainda descreve outros cenários, tais as coleções de museus de etnologia e arqueologia, as reuniões de pesquisadores nos seminários de Cambridge, e as atividades de preparação da exposição no Museu Nacional de Papua Nova Guiné. Em sua crítica às noções de classificação e continuidade temporal, Moutu também problematiza alguns pontos da teoria da agência dos objetos de arte em Alfred Gell (1998), onde haveria uma "sobredeterminação" da análise por um viés demasiadamente preso às leituras da fenomenologia e das ciências cognitivas.

O capítulo assinado por Rebecca Empson (2007) é um dos melhores trabalhos deste livro. Sua etnografia a respeito das práticas de separação e reunião de pessoas e coisas na Mongólia oferece uma interessante abordagem desta complexa e diversa sócio-cosmologia, vista mediante fotografias, espelhos, roupas e ornamentos. É a partir destas coisas que a autora procura apreender o conceito de fortuna (xishig) que permeia diversos aspectos da vida social mongol. Desta maneira, percorre um caminho inovador ao tratar as relações de parentesco instanciadas por esses objetos, presentes em todas as casas mongóis. Essas relações são literalmente passíveis de serem "vistas" por intermédio da disposição destas coisas no interior das casas, em orientações estéticas (e éticas) que tornam possível a leitura das relações de parentesco (passadas e presentes) a qualquer um que as adentrar. Como o povo com os quais a autora esteve e estudou tem hábitos nômades, a disposição de artefatos nas casas que deixam pra trás são como mapas das relações aos olhos dos que chegam e a encontram "vazia" (EMPSON, 2007, p. 116). Toda essa "parafernália" da 
MESSIAS BASQUES - Uma antropologia das coisas...

vida social mongol pode ser assim vista como extensão de relações e de pessoas. Sendo assim, as pessoas não estão somente onde se encontram seus corpos, mas em diferentes lugares e de modo simultâneo; são pessoas distribuídas (Cf. STRATHERN, 1994; GELL 1998). A presença corporal não é condição necessária à manutenção das relações neste regime de divisibilidade da pessoa. Logo, Rebecca Empson propõe que a separação deve ser compreendida como o cerne da ontologia de coisas e pessoas nos processos de objetificação que as concerne.

No capítulo seguinte, Morten Axel Pedersen (2007) aborda questões similares ao descrever os talismãs do pensamento nas ontologias xamânicas dos Darhad do Norte da Mongólia. O foco do seu trabalho de campo se refere às coisas utilizadas nos rituais xamânicos, as quais tornam visível uma ontologia social oculta aos olhos das demais pessoas. Há aqui uma proveitosa discussão sobre o xamanismo dos povos amazônicos sob regime perspectivista em face dos xamãs Darhad, ambos tradutores de mundos outros e transeuntes da perigosa relação de troca de corpos e seus pontos de vista (CARNEIRO DA CUNHA, 1998; VIVEIROS DE CASTRO 1998a e 1998b). O vestuário empregado no xamanismo Darhad é concebido por Pedersen como uma tecnologia sócio-cognitiva diretamente relacionada a uma ontologia que, por conseguinte, deve ser apreendida em termos daquilo que Martin Holbraad (2003) chamou de "ontografia", uma vez que não se trata aqui somente de uma atividade de conhecimento tal como a concebemos no Ocidente. O autor se aproxima de Eduardo Viveiros de Castro (1998b) ao endossar a sua diferenciação entre "olhar" (como estado ontológico definido pelo engendramento de uma perspectiva de tipo específico no mundo) e "conhecer" (como estado epistemológico de reflexão sobre o mundo).

O penúltimo capítulo é dedicado a uma crítica da teoria da abdução da criatividade, elaborada por Alfred Gell em "Art and Agency" (1998). James Leach (2007) parte da crítica aos usos da categoria de "material", vista como domínio do "inanimado", nas teorias antropológicas que a tomam como dado pré- analítico: um dos blocos básicos sobre o qual uma teoria dos significados sociais (ou culturais) costuma ser erigida. Seu trabalho de campo se deu no acompanhamento 
MESSIAS BASQUES - Uma antropologia das coisas...

de iniciativas de colaboração entre cientistas e artistas em torno do recente campo das "sci-arts". Novamente, trata-se de evidenciar os limites da teoria de Alfred Gell. Embora sejam pertinentes as ponderações feitas, o que deveríamos ter em conta é o avanço possibilitado pelos trabalhos de Gell em seu esforço de (re)atualizar a discussão em torno do estatuto da comparação em antropologia; Gell não tratou de comparar para generalizar, mas antes de generalizar - isto é, construir hipóteses - para depois pôr à prova os conceitos criados em face das comparações possibilitadas por teorias etnográficas distintas. James Leach (2007) procura tirar proveito de uma interessante proposição de Gell a respeito do "encantamento que é imamente a todos os tipos de atividade técnica" (GELL, 1999, p. 163-164) para tratar uma questão que este autor não problematizou, a saber, a possibilidade de conceber uma "criatividade apropriativa" produzida em "colaboração", na qual não haveria agentes de primeira ou segunda classe, "atores" e "objetos agidos".

O capítulo que encerra a coletânea oferece uma contribuição inovadora ao clássico debate acerca da noção de mana, atualizando-o mediante etnografia no Ifá cubano. Martin Holbraad (2007) diz que após a célebre introdução de Claude Lévi-Strauss à obra de Marcel Mauss, poucos foram os trabalhos que conseguiram problematizar o debate noutros termos e horizontes. E tributa a Eduardo Viveiros de Castro (1998a, 1998b, 2002, 2004 e 2005) e Márcio Goldman (2003 e 2004) algumas das leituras que o inspiraram a retomar os problemas lévistraussianos - como o de mana - a fim de oferecer alternativas ao aporte estruturalista. Donde a possibilidade de descrever ontologias em termos outros que não (primordialmente) os de sistemas de classificação. Martin Holbraad (2007) procura traçar uma descrição que dê conta de apreender, simultaneamente, ambas as dimensões constitutivas do aché no Ifá cubano: coisa e conceito, pó e poder, onde o pó fornece a condição a partir (e mediante a qual) as divindades podem se manifestar num plano de imanência. E a conclusão que o autor nos oferece aponta para o fato de que a mobilidade do pó dissolve - problema da transcendência versus imanência para os babalowos, dissolvendo também o problema da oposição entre conceitos e coisas. 
MESSIAS BASQUES - Uma antropologia das coisas...

Portanto, se neste universo logicamente móbil o pó pode ser poder, divindades podem ser inscritas e vistas nos oráculos de Ifá.

Como epílogo e convite à leitura desta coletânea de teorias etnográficas, restaria então dizer que a vantagem de empregar o termo "coisas" é que, diferentemente de "objetos", "artefatos" e "materialidade", elas trariam consigo uma mínima bagagem teórica: o termo se distingue por sua vacuidade peculiar. O uso (neste sentido, despojado) do termo "coisas" também procura demarcar uma mudança de status: enquanto análises sentenciam, exercícios heurísticos localizam, cartografam. Os autores deste livro propõem uma metodologia através da qual as coisas elas mesmas possam ditar uma pluralidade de ontologias. Pois se o pressuposto sempre foi de que a antropologia é uma episteme - ainda que uma episteme das epistemes de outros, que nós chamamos de culturas -, então, se nos recusamos a atribuir diferenças à cultura e similaridade à natureza, a coerção circular do dualismo seria assim dissolvida. No esquema desenvolvido pelos autores, a pressuposição de uma unidade natural e de uma diferença cultural - subsumida no anthropos - já não se faz sustentável, e nem sequer necessária.

Tal guinada ontológica em antropologia refuta prontamente tais pressuposições. A noção de 'muitos mundos' é distinta da idéia familiar de uma 'pluralidade de visões de mundo' justamente por que ela incide na modesta admissão - assim logicamente pensada - de que nossos conceitos (não nossas 'representações') devem, por definição, ser inadequados à tradução de outros, diferentes. Este deveria ser, todavia, o único meio de tomar seriamente a diferença - alteridade - como ponto de partida da análise antropológica. É por tal razão, por exemplo, que não podemos compreender a alegação dos divinadores cubanos quando dizem que o pó é poder em termos de um argumento 'construtivista' (Cf. LATOUR, 1999, p. 21-3). Para colocar em termos foucauldianos, o ponto não é que alegações discursivas (como, 'pó é poder') ordenem a realidade de modos diferentes - de acordo com regimes de verdade também diferentes -, mas antes que tais enunciações criam novos objetos (como um pó poderoso) no ato mesmo de enunciação de novo conceitos (como 'pó poderoso'). 
MESSIAS BASQUES - Uma antropologia das coisas...

O que os autores procuraram desenvolver é, se o leitor preferir, um tipo inteiramente diferente de construtivismo, um "construtivismo não humanista" (Cf. DELEUZE e GUATTARI, 1992). O discurso pode ter efeitos não porque ele "sobredetermina a realidade", mas antes porque não há nem deve haver qualquer distinção ontológica entre "discurso" e "realidade". Noutras palavras, conceitos podem denotar coisas justamente por que conceitos e coisas correspondem a uma e a mesma "coisa". Donde a alteridade possa então ser pensada como uma propriedade das coisas - coisas que são conceitos tanto quanto elas se nos apresentam como entidades 'físicas' ou 'materiais'. Portanto este é um método para 'voltar às coisas elas mesmas', como diriam os fenomenólogos, mas somente se atentarmos que este método não partilha a concepção de que no "mundo- da-vida" nossa "experiência" das coisas tem prioridade sobre "atitudes teóricas". Mais precisamente, por que nossa experiência das coisas pode ser conceitual.

Porém, se as coisas são diferentes, por que elas apresentam-se como as mesmas? Se 'mundos diferentes' situam- se nas coisas, por assim dizer, então como fomos capazes de não percebê- los por tanto tempo? O ponto que concerne a 'mundos diferentes' se refere ao fato de que eles não podem ser 'vistos' numa acepção 'visual'. Eles são invisíveis. Ou seja, a dissolução da distinção entre conceitos e coisas (aparência e realidade) nos leva, ao mesmo tempo, a conceber outro modo de 'revelação'. A questão que assim surge incide sobre como as coisas encontradas no curso do trabalho etnográfico tornam-se aparentes. E não se trata aqui de simplesmente descartar um pressuposto antropológico de 'episteme de todas as epistemes' em prol de uma ontologia de todas as ontologias. Ao invés disso, herdeiros das deficiências de uma ontologia dualista (e do racionalismo científico que a erigiu), estaríamos carentes de uma metodologia apta a recuperar o crédito que as pessoas (e coisas) com as quais estudamos deveriam ter.

Os autores desta coletânea defendem que precisamos investir numa metodologia que nos dê acesso à produção dos conceitos que fazem tais mundos. Este movimento - a relação recursiva entre o que concerne ao campo e as posturas metodológicas dos etnógrafos - deve muito ao conceito de "invenção" cultural, de Roy Wagner (1981 e 1986). Um dos principais aspectos de Invention of Culture (WAGNER, 1981) é a 
MESSIAS BASQUES - Uma antropologia das coisas...

descrição sistemática dos recursos de que os antropólogos lançam mão ao 'inventarem' as culturas que estudam. A inovação - tão central ao argumento aqui desenvolvido - refere-se ao fato de que a noção Wagneriana de invenção não se contrapõe nem à 'realidade' nem é construída como uma propriedade exclusiva ao gênio humano. Assim entendida, a noção apresenta-se como modo mediante o qual a realidade (ou 'mundos', poderíamos dizer) é constituída - um exercício ontológico por excelência. Para Wagner, invenção é apenas o processo pelo qual os conceitos são transformados no ato mesmo em que os 'aplicamos' a novos contextos, para que, rigorosamente falando, os conceitos carreguem seus contextos no interior de si mesmos (WAGNER, 1986; STRATHERN, 1990).

Tal como Marylin Strathern, Wagner vê o encontro entre os conceitos do antropólogo e aqueles oriundos do campo como produtivo pela divergência que suscita. Quando ambos estão em contato, seus sentidos se transformam através daquilo que Wagner denominou "extensão metafórica" (WAGNER, 1981, p. 38- 39). Tal relação recursiva, entre o que os "informantes" fazem e as técnicas que os antropólogos empregam ao estudá-los, também é fundamental para a estratégia desta coleção. Isto posto, o argumento meta-antropológico acerca do valor de pensar mediante as coisas seria uma capitulação holográfica para usar o idioma Melanesianista - para o impacto coletivo dos estudos etnográficos aqui reunidos.

Alhures, em ensaio a respeito das fotografias da coleção pessoal de Mário de Andrade, e numa espécie de 'filosofia das coisas', Bento Prado Júnior (2006) propôs que 'imaginar' não é o contrário de investigar o mundo objetivo: é abrir-se para o que, até agora, permaneceu 'in-visível'. É a reflexão convidada a se instaurar noutros pontos que não aqueles do "certo" e "verdadeiro".

Sem a imaginação ou a variação sistemática do modo de ver, não poderíamos topar com e descobrir os indícios que podem levar-nos ao código iluminador da obra em sua singularidade (assim como descobrir ou ver de modo diverso o próprio código a partir da obra singular). Sem saper vedere não poderemos, mesmo fora das artes plásticas e da Estética, saper leggere e saper ascoltare, isto é, re-ver nossa experiência quotidiana, nossa relação com a sociedade, com a 
MESSIAS BASQUES - Uma antropologia das coisas...

cultura e com o mundo. Noutras palavras, estaremos condenados a permanecer aquém da filosofia (PRADO JÚNIOR, 2006, p. 36 - grifos no original).

E caso o leitor queira outra referência de uma proposição similar, lembremos o interessante experimento filosófico de François Jullien (2001) acerca do diálogo 'ficcional' (e, mais que isso, heurístico) entre um pensador chinês do século IV a.C. e um filósofo das Luzes. Pois em ambos os casos trata- se de tomar distâncias das convenções teóricas de que dispomos para pensar mediante tomadas de vistas que possam engendrar instrumentos teóricos renovados, fazendo de tais conexões transversais (e insuspeitas), método.

E o que diríamos? Estamos cientes de que - muitas vezes - nos colocamos aquém da antropologia? Porquanto a promessa de pensar mediante as coisas não implica oferecer teorias consumadas, mas antes um método capaz de gerar uma pluralidade de conceitos e teorias. $\mathrm{E}$ talvez seja por essa razão que não há neste livro um movimento homogêneo no que concerne às ressonâncias dos autores que figuraram a chamada 'revolução silenciosa' das últimas três décadas. A ênfase na metodologia tem por objetivo a aproximação de propostas teóricas distintas, elaboradas nos mais diversos encontros etnográficos, num experimento coerentemente atravessado por um mínimo método comum. O programa positivo de pensar mediante as coisas nos desobriga da filiação a boticários e alienistas, uma vez que o contraste idiomático suscitado pela etnografia torna- se a premissa por excelência das teorias antropológicas assim concebidas e inventadas.

\section{Referências bibliográficas}

BATESON, Gregory. Naven. São Paulo: Edusp, 2008.

CARNEIRO DA CUNHA, Manoela. Pontos de vista sobre a Floresta Amazônica: xamanismo e tradução. Mana, Rio de Janeiro, v. 4, n. 1, p. 7-22, 1998.

DELEUZE, Gilles; GUATTARI, Félix. O que é a filosofia? São Paulo: Editora 34, 1992. 
MESSIAS BASQUES - Uma antropologia das coisas...

DUPUY, Jean-Pierre. Nas origens das ciências cognitivas. São Paulo: UNESP, 1995.

EMPSON, Rebecca. Separating and containing people and things in Mongolia. In: HENARE, Amiria et al. Thinking through things: theorizing artefacts ethnographically. London/New York: Routledge, 2007. p.113-140.

GELL, Alfred. Art and agency. Oxford: Oxford University Press, 1998.

The art of anthropology. Oxford: Berg Publishers, 1999.

GOLDMAN, Márcio. Observações sobre o sincretismo Afro-Brasileiro. Revista Anual do Núcleo de Estudos Afro-Baianos Regionais da Universidade Estadua1 de Santa Cruz, Santa Cruz, v. 1, n. 1, p. 132-137, 2003.

Série, estrutura, devir: Lévy-Bruhl, Deleuze e o Candomblé. In: Encontro Anual da ANPOCS, 28, 2004. Caxambú: XXVIII Encontro Anual da ANPOCS, 2004.

HENARE, Amiria. Taonga Mäori: encompassing rights and property in New Zealand. In: HENARE, Amiria et al. Thinking through things: theorizing artefacts ethnographically. London/New York: Routledge, 2007. p. 47-67.

HENARE, Amiria et al. Thinking through things: theorizing artefacts ethnographically. London/New York: Routledge, 2007.

HOLBRAAD, Martin. Estimando a necessidade: os oráculos de Ifá e a verdade em Havana. Mana, Rio de Janeiro, v. 9, n. 2, p. 39-77, 2003.

The Power of powder: multiplicity and motion in the divinatory cosmology of Cuban Ifá (or mana, again). In: HENARE, Amiria et al. Thinking through things: theorizing artefacts ethnographically. London/New York: Routledge, 2007. p. 189-225.

INGOLD, Tim. The perception of the environment: essays in livelihood, dwelling, and skill. London: Routledge, 2000.

JULLIEN, François. Fundar a moral: diálogo de Mêncio com um filósofo das luzes. São Paulo: Discurso, 2001.

LATOUR, Bruno. Discussion: for David Bloor... and beyond: a reply to David Bloor's anti-Latour. Studies in the History and Philosophy of Science, Elsevier, v. 30, n. 1, p.113-129, 1999.

LEACH, James. Differentiation and encompassment: a critique of Alfred Gell's theory of the abduction of creativity. In: HENARE, Amiria et al. Thinking through things: theorizing artefacts ethnographically. London/New York: Routledge, 2007. p.167-188.

LÉVI-STRAUSS, Claude. Olhar, ouvir, ler. Lisboa: Edições ASA, 1995.

MACHADO DE ASSIS, Joaquim Maria. O Alienista. São Paulo: Ática, 1992.

Espaço Ameríndio, Porto Alegre, v. 4, n. 1, p. 150-165, jan./jun. 2010. 
MESSIAS BASQUES - Uma antropologia das coisas...

MAUSS, Marcel. Ensaio sobre a dádiva: forma e função da troca na sociedade arcaica. In: Sociologia e Antropologia. São Paulo: Cosac\&Naify, 2003. p. 183-314.

MOUTU, Andrew. Collection as a way of being. In: HENARE, Amiria et al. Thinking through things: theorizing artefacts ethnographically. London/New York: Routledge, 2007. p. 93-112.

PEDERSEN, Morten Axel. Talismans of thought: shamanist ontologies and extended cognition in northern Mongolia. In: HENARE, Amiria et al. Thinking through things: theorizing artefacts ethnographically. London/New York: Routledge, 2007. p. 141-166.

PIGNARRE, Philippe; STENGERS, Isabelle. La sorcellerie capitaliste: pratiques de desenvoûtement. Paris: La Découverte, 2005.

PRADO JÚNIOR, Bento. Entre Narciso e o colecionador, ou o ponto cego do criador. Revista do IEB, São Paulo, n. 43, p. 9-36, 2006. Disponível em: http://www.revistasusp.sibi.usp.br/pdf/rieb/n43/a01n43.pdf . Acesso em: 28 jun. 2010.

RABINOW, Paul. Marking Time: on the anthropology of the contemporary. Princeton: University Press, 2008.

REED, Adam. Smuk is king: the action of cigarettes in a Papua New Guinea Prison. In: HENARE, Amiria et al. Thinking through things: theorizing artefacts ethnographically. London/New York: Routledge, 2007. p. 32-46.

SAHLINS, Marshall. Islands of History, Chicago: University of Chicago Press, 1985.

STRATHERN, Marylin. The gender of the gift: problems with women and problems with society in Melanesia, Berkeley: University of California Press, 1988.

. Artefacts of history: events and the interpretation of images. In: SIIKALA, Jukka. (Org). Culture and History in the Pacific. Helsinki: Finnish Anthropological Society, 1990. p. 24-44.

One-Legged Gender. In: TAYLOR, Lucien. (Org.). Visualizing theory: selected essays. New York/London: Routledge, 1994. p. 241-251.

Partial Connections. Walnut Creek: Altamira Press, 2004.

TARDE, Gabriel. Monadologia e sociologia e outros ensaios. São Paulo: Cosac Naify, 2007.

VIVEIROS DE CASTRO, Eduardo. Cosmological Perspectivism in Amazonia and Elsewhere: four lectures delivered 17 February-10 March at the Department of Social Anthropology. Cambridge: University of Cambridge, 1998a. 
Cosmological deixis and Amerindian perspectivism. Journal of the Roya1 Anthropological Institute, Londres, v. 4, n. 3, p. 469-488, 1998 b.

. O nativo relative. Mana, v. 8, n. 1, p. 113-148, 2002.

The forest of mirrors: notes on the ontology of Amazonian spirits. Chicago: University of Chicago, 2004.

. The gift and the given: three nano-essays on kinship and magic. In: BAMFORD, Sandra; LEACH, James (Orgs.). Genealogy beyond kinship: sequence, transmission, and essence in ethnography and Social Theory. Oxford: Berghahn Books, 2005. p. 237-268.

WAGNER, Roy. The invention of culture. Chicago: University of Chicago Press, 1981. 1986.

Symbols that Stand for Themselves, Chicago: University of Chicago Press,

WASTELL Sari. The 'legal thing' in Swaziland: res judicata and divine kingship. In: HENARE, Amiria et al. Thinking through things: theorizing artefacts ethnographically. London/New York: Routledge, 2007. p. 68-92. 